4th Global Business Research Congress, May 24-25, 2018, Istanbul, Turkey.

\title{
STRESS FACTORS AFFECTING JOB SATISFACTION AND JOB SATISFACTION IN HEALTH CARE WORKERS: AKDENIZ UNIVERSITY HOSPITAL NURSING SERVICES EXAMPLE
}

DOI: 10.17261/Pressacademia.2018.865

PAP- V.7-2018(18)-p.116-121

Turhan Turan'1, Yildirim Beyazit Gulhan², Salim Yilmaz ${ }^{3}$

${ }^{1}$ Okan University, Istanbul, Turkey.

turhan.turan@hotmail.com, ORCID: 0000-0002-6583-6488

${ }^{2}$ Okan University, Istanbul, Turkey.

yildirim.gulhan@okan.edu.tr, ORCID: 0000-0002-9681-0248

${ }^{3}$ Okan University, Istanbul, Turkey.

salim.yilmaz@okan.edu.tr, ORCID: 0000-0003-2405-5084

To cite this document

Turan, T., Gulhan, Y. B., Yilmaz, S. (2018). Stress factors affecting job satisfaction and job satisfaction in health care workers: Akdeniz University Hospital nursing services example. PressAcademia Procedia (PAP), V.7, p.116-121.

Permemant link to this document: http://doi.org/10.17261/Pressacademia.2018.865

Copyright: Published by PressAcademia and limited licenced re-use rights only.

\section{ABSTRACT}

Purpose- The aim of the study is to investigate the job satisfaction and the stress factors affecting the nursing service employees in the Akdeniz University Hospital and to determine the factors affecting job stress and job satisfaction levels.

Methodology- The study is a questionnaire study and the universe is composed of 795 Nurses working in Akdeniz University Hospital. Simple Random Sampling Method A survey study was conducted on 308 people. Reliability and validity of the survey conducted in Turkey Baltas (1998) Job Stress Scale and Minnesota Job Satisfaction Scale was used by carried. The Cronbach Alpha value was found to be 0.84 . In the analysis of the data, frequency, percentage, standard deviations were used. Analyzes were performed in SPS 22.0 program.

Findings- Significance was determined statistically in the internal, external and general satisfaction dimensions according to the education levels of the participants, occupational seniority and income level. In addition, as levels of stress decreased in participants, job satisfaction levels also decreased. Participants' stress scores were negatively correlated with internal external and general satisfaction dimensions and internal, external and general satisfaction decreased as stress levels increased.

Conclusion- As a result of the study, education status, seniority, income level and willingness factors were found to have a significant effect on job satisfaction. It was understood that job stress, which is at a positive level, increased job satisfaction.

Keywords: Job satisfaction, stress, nurse, job satisfaction dimensions, job satisfaction.

JEL Codes: M10, M12, J53

\section{SAĞLIK ÇALIŞANLARINDA IŞ DOYUMU VE IŞ DOYUMUNU ETKILEYEN STRES FAKTÖRLERI (AKDENIZ ÜNIVERSITESI HASTANESI HEMŞIRELIK HIZMETLERI ÖRNEĞi)}

\section{ÖZET}

Amaç- Çalışmanın amacı Akdeniz Üniversitesi Hastanesinde Hemşirelik Hizmetleri çalışanlarııın iş doyumunu ve onu etkileyen stres faktörlerini araştırmak, iş stresi ve iş tatmini düzeylerine etki eden faktörleri belirlemektir.

Yöntem- Çalışma anket çalışması olup, evrenini Akdeniz Üniversitesi Hastanesinde çalışan 795 Hemşire oluşturmaktadır. Basit Rastgele Örnekleme Yöntemi 308 kişi üzerinde anket çalışması yapılmışır. Ankette Türkiyede geçerlilik ve güvenilirliği yapılmış Baltaş (1998) tarafından gerçekleştirilen İ̧̧ Stres Ölçeği ve Minnesota iş̧ Doyum Ölçeği kullanılmıştır. Cronbach Alpha değeri 0.84 bulunmuştur. Verilerin analizinde frekans, yüzde, standart sapma yöntemlerinden yaralanılmışıtr. Analizler SPS 22.0 programında gerçekleştirilmiştir.

Bulgular- Katılımcıların eğitim düzeylerine, Mesleki kıdeme ve Gelir düzeyine göre, içsel, dışsal ve genel doyum boyutlarında istatistiksel olarak anlamlıık saptanmışıı. Ayrıca katılımcılarda stres düzeyleri azaldıkça iş doyum düzeylerinin de azaldığı görülmüştür. Katılımcıların stres puanları ile içsel dışsal ve genel doyum boyutları arasında negatif yönlü bir ilişki olup stres düzeyleri arttıkça içsel, dışsal ve genel doyumları azaldığı görülmüştür.

Sonuç- Çalışma sonucunda eğitim durumu, kıdem, gelir düzeyi ve işini isteyerek yapma faktörlerinin iş doyumuna önemli etki yaptığı görülmüştür.Bunun yanı sıra iş stresinin olumlu seviyede olması iş doyumunu arttırdığı anlaşılmıştır.

Anahtar Kelimeler: iş̧ doyumu, stres, hemşire, iş doyum boyutları, iş tatmini.

JEL Kodları: M10, M12, J53 


\section{GíRiş}

Sağlık kurumları, hastaneler gibi sağlık hizmetleri sunarak toplumun sağlık düzeyini yükseltmeyi hedefleyen kuruluşlar bir yandan hizmetlerini sürdürürken bir yandan da bilimin, teknolojinin ve çağın getirdiği yenilikleri takip ederek bir gelişme hedeflerinin olması gereklidir. Bu kuruluşların kendilerini geliştirme çabasında başarıya ulaşması için en önemli faktör çalışanlar yani insan faktörüdür. Çalışma yaşamı her birey için ayrı bir anlam ifade etmektedir. Kimileri için ekonomik kazanç, bir zorunluluk, kimileri içinse bir zevk, sosyal statü gibi anlamlar taşımaktadır. Çalışma yaşamında işlerini daha çok seven, daha çok haz alan, hoşnutluk duygusu yüksek bireyler işlerinde daha başarılı, daha verimli olup, gerek iş, gerek sosyal ilişkilerinde daha iyi iletişim kurduğu ve bunların sonucunda daha sağlıklı bir yaşam sürdüğü görülmüştür.

Bu araştırmanın temel amacı, sağlık çalışanlarında iş doyumu düzeyleri ve iş doyum düzeylerini etkileyen stres faktörlerini belirlemek; sağlık çalışanlarının iş doyumunu yükseltmek ve stres faktörlerini azaltmak için ilgili öneriler getirmektir.

\section{LITERATÜR INCELEMESI}

"iş tatmini, 'işten elde edilen maddi çıkarlar ve iş görenin beraber çalışmaktan zevk aldığı iş arkadaşları ile bir eser meydana getirmesinin sağladığı mutluluk' şeklinde tanımlanabilir. Eğer iş̧̧ çalışması sonucunda ortaya koyduğu eseri somut olarak görebiliyorsa, bundan duyacağı gururu onun için tatmin kaynağı olacaktır" (Şimşek vd., 2007, ss.139-150).

"İ̧̧ doyumu, kişinin işine olduğu olumlu etki ya da duygulardır. Başka bir deyişle iş doyumu, iş görenlerin duydukları hoşnutluk ya da hoşnutsuzluktur" (Davis vd., 1989, s. 177).

Şahin, ilgili tezinde stresi tanımlarken kullandığı aktarmasında konuya şu şekilde değinmiştir: "1926 yılında Walter Cannon vücudun acil/tehlikeli bir duruma karşı verdiği tepkiyi açıklamak için "savaş ya da kaç" kavramını tanımlamıştır. Cannon'a göre stres, organizmanın kendi yaşamını ve çevreye uyumunu (dengesini) tehdit eden bir unsura (uyarıııya) karşı gösterdiği varoluş nedeni olan bir "savaşma ya da kaçma" tepkisidir. Bir tehlike ile karşılaşan canlı, başa çıkamayacağına inandığında ise tehlike ile savaşır ve yeni duruma uyum sağlar" (Şahin, 2011, ss.11-39)

\section{VERI VE YÖNTEM}

Bu çalışmanın evreni Akdeniz Üniversitesi Hastanesinde çalışan Hemşirelik mesleği mensuplarıdır. 2016-2017 yılında hastanede görev yapan 795 personel olduğu bilinmektedir. Basit Rastgele Örnekleme Yönetimi ile \%5 hata ile 298 kişi olduğu hesaplanmıştır. Akdeniz Üniversitesi Hastanesinde çalışan Hemşireler kapsamında yapılan çalışmamızda 308 Adet anket çalışması gerçekleştirilmiştir. Yapılan anket çalışmasında Minnesota İş Doyum Ölçeği ve İş Stres Ölçeği olmak üzere 2 farklı ölçek tipi kullanılmıştır. Illk olarak Minnesota İ̧ Doyum Ölçeği 1-5 arasında puanlanan beşli likert tipi bir ölçektir. Anket soruları, İçsel Doyum (aşarı, tanınma veya takdir edilme, işin kendisi, işin sorumluluğu, yükselme ) ve Dışsal Doyum (iş̧letme politikası ve yönetimi, denetim şekli, yönetici, çalışma ve astlarla ilişkiler, çalışma koşulları, ücret) olmak üzere 2 boyutta ölçüm yapmayı amaçlar. Bu ikisinden elde edilen puan Genel Doyum puanıdır.

Cronbach Alpha iki ölçek için ayrı ayrı yapılmış ve ortalamaları 0,88 bulunmuş olup güvenilirlik analizi oldukça yüksek olarak kabul edilmiştir. İ̧ Stresi Ölçeği Cohen ve Williamson (1988) tarafından geliştirilmiştir. Türkiye'deki geçerlilik ve güvenilirliği Baltaş (1998) tarafından yapılan ölçeğin, Cronbach Alpha değeri 0.84 bulunmuştur. Faktör yapılarına bakıldığında varyansın \%66'sını test eden Kaiser-Meyer-Olkin katsayısı 0,81 olarak bulunmuş olup, Barlett testi sonucu $\mathrm{p}=0,05$ 'ten küçük çıkmıştır. Faktör yapılarının tespitinde eksen döndürmeleri Varimax yöntemi ile yapılmışır

Çalışmada kullanılan iş Stres ölçeğinde gruplara karşılık gelen ifadeler belirlenmiştir. Bunlar aşağıdaki gibidir:

A (1.Grup) : Sağlığı ve verimliliği ciddi olarak tehdit eden ağır risk düzeyi (1,0-1,3 puan)

B (2.Grup) : Kişiye önemli olduğunu hissettirmeyen, onun kapasitesini kullanmasına imkân vermeyen ve yeterli uyarım sağlamayan, dolayısıyla can sıkıntısından ve önemsizlik duygusundan kaynaklanan stres düzeyi (1,4-1,9 puan).

C (3.Grup) : Uyarıcı yönleri olan, ancak hafif bir iş. Başarı güdüsü yüksek biri için sıkıcı, mücadeleci olmayan biri için uygun bir iş stresi düzeyi (2,0-2,5 puan)

D (4.Grup) : Sağı̆ık ve verimlilik açısından en elverişli iş stersi düzeyi (2,6-3,1 puan).

E (5.Grup) : Uyarıcılığı yüksek, sorumluluğu fazla ancak kişiye çekici gelen iş stresi düzeyi. Bazı yönleriyle kişiyi zorlayarak verimliliği artırırken, bazı yönleriyle tehdit edebilir(3,2-3,4 puan).

F (6.Grup) : Sorumluluk düzeyi yüksek, kişiyi zaman açısından zorlayan, dinlenmeye ve aile ilişkilerine imkân tanımayan, bu sebeple sağlık ve verimlilik için tehdit oluşturan stres düzeyi (3,5-4,0 puan).

Çalışmada tanımlayıcı istatistikler frekans, yüzde, ortalama, standart sapma değerlerinden yararlanılmıștır. elde edilen boyutlardaki iki grubun ölçüm değerleri arasındaki farkın analizinde bağımsız $t$ testi kullanılmışı̆ı. Üç evre grubun karşılaştırılmasında Varyans analizi (ANOVA) testi kullanılmıştır. Anlamlı çıkanlar Dunn-Sidak ile ikili karşılaştırmalara tabi tutulmuştur. Boyutlarının arasındaki ilişkilerin tespit edilmesi amacı ile korelasyon analizi ve ilişkilerin modellenmesi amacı ile regresyon analizi uygulaması yapılmıştır. Analizler SPSS 22.0 paket programı ile yapılmıştır. Çalışma hipotezleri ise şunlardır:

H1:Akdeniz Üniversitesi Hastanesindeki sağlık çalışanlarının iş tatmini düzeyleri ile işs stresi düzeyleri arasında negatif ilişki vardır.

H2: Akdeniz Üniversitesi Hastanesindeki sağılı çalışanlarının stres tiplerine göre iş tatmini düzeyleri farklıdır 
H3:Akdeniz Üniversitesi Hastanesindeki sağlık çalışanlarının demografik ve iş ile ilgili özellikleri iş tatmini üzerinde etkilidir.

\section{BULGULAR}

Tablo 1: Katılımcıların Demografik Özellikleri

\begin{tabular}{|c|c|c|}
\hline Yaş Durumu & $\mathbf{n}$ & $\%$ \\
\hline $20-24$ & 54 & 17,5 \\
\hline $25-29$ & 70 & 22,7 \\
\hline $30-34$ & 44 & 14,3 \\
\hline $35-39$ & 81 & 26,3 \\
\hline $40-45$ & 48 & 15,6 \\
\hline 46 Üzeri & 11 & 3,6 \\
\hline Toplam & 308 & 100,0 \\
\hline Medeni Hal Durumu & $\mathrm{n}$ & $\%$ \\
\hline Evli & 180 & 58,4 \\
\hline Bekar & 128 & 41,6 \\
\hline Toplam & 308 & 100,0 \\
\hline Eğitim Durumu & $\mathrm{n}$ & $\%$ \\
\hline Sağlık Meslek Lisesi & 44 & 14,3 \\
\hline Önlisans & 45 & 14,6 \\
\hline Lisans & 177 & 57,5 \\
\hline Lisansüstü & 42 & 13,6 \\
\hline Toplam & 308 & 100,0 \\
\hline Kaç Yıldır Çalıştığı & $\mathrm{n}$ & $\%$ \\
\hline 1 Yıldan Az & 7 & 2,3 \\
\hline 1-5 Yll & 99 & 32,1 \\
\hline $6-10$ YII & 57 & 18,5 \\
\hline 11 Yıl Ve Üzeri & 145 & 47,1 \\
\hline Toplam & 308 & 100,0 \\
\hline Gelir Durumu & $\mathrm{n}$ & $\%$ \\
\hline Gelir Giderden Az & 164 & 53,2 \\
\hline Gelir Gider Denk & 20 & 6,5 \\
\hline Gelir Giderden Fazla & 124 & 40,3 \\
\hline Toplam & 308 & 100,0 \\
\hline Çalışma Şekli & $\mathrm{n}$ & $\%$ \\
\hline Sürekli Gündüz & 109 & 35,4 \\
\hline Sürekli Gece & 10 & 3,2 \\
\hline Gece Gündüz Nöbet Sistemi & 189 & 61,4 \\
\hline Toplam & 308 & 100,0 \\
\hline
\end{tabular}

Çalışmaya katılan personelin \%26'sının 35-39 yaş aralığında olduğu, \%58'inin \%57.5'inin lisans düzeyinde eğitime sahip olduğu \%47'si 11 yıldan fazla mesleğini yaptığı \%53'nün giderinin gelirden fazla olduğu, \%61'i ise değişken vardiya sisteminde çalıştığı görülmüştür.

\section{Tablo 2: İşini Severek Yapma ve Boyutlar}

\begin{tabular}{|c|c|c|c|c|c|c|}
\hline Boyutlar & $\begin{array}{l}\text { İşinizi isteyerek mi } \\
\text { yapıyorsunuz? }\end{array}$ & $\mathrm{n}$ & $x$ & s.s & $\mathbf{t}$ & $\mathbf{p}$ \\
\hline \multirow{2}{*}{ İçsel Doyum } & Evet & 213 & 3,39 & 0,47 & \multirow{2}{*}{10,13} & \multirow{2}{*}{0,01} \\
\hline & Hayır & 95 & 2,71 & 0,68 & & \\
\hline \multirow{2}{*}{ Dışsal Doyum } & Evet & 213 & 2,99 & 0,62 & \multirow{2}{*}{7,10} & \multirow{2}{*}{0,01} \\
\hline & Hayır & 95 & 2,43 & 0,66 & & \\
\hline \multirow{2}{*}{ Genel Doyum } & Evet & 213 & 3,19 & 0,50 & \multirow{2}{*}{9,15} & \multirow{2}{*}{0,01} \\
\hline & Hayır & 95 & 2,57 & 0,64 & & \\
\hline
\end{tabular}

Tablo 2'de bağımsız $t$ testiyle İşini İsteyerek yapma ve doyum boyutları arasındaki ilişki incelenmiştir. Buna göre farkın sebebinin işini severek yapan katılımcıların doyum düzeyleri işini sevmeden yapan katılımcılara göre anlamlı derecede daha yüksek olduğu tespit edilmiştir $(p=0,01<0,05)$. 
Tablo 3: Eğitim ve Boyutlar

\begin{tabular}{|c|c|c|c|c|c|c|}
\hline Boyut & Meslek & $\mathbf{n}$ & $x$ & s.s & $\mathbf{F}$ & $\mathbf{p}$ \\
\hline \multirow{4}{*}{ İçsel Doyum } & Sağlık meslek lisesi & 44 & 3,30 & 0,31 & \multirow{4}{*}{4,80} & \multirow{4}{*}{0,01} \\
\hline & önlisans & 45 & 3,46 & 0,55 & & \\
\hline & Lisans & 177 & 3,10 & 0,62 & & \\
\hline & Lisansüstü & 42 & 3,10 & 0,86 & & \\
\hline \multirow{4}{*}{ Dışsal Doyum } & Sağlık meslek lisesi & 44 & 2,94 & 0,57 & \multirow{4}{*}{3,84} & \multirow{4}{*}{0,01} \\
\hline & önlisans & 45 & 3,07 & 0,68 & & \\
\hline & Lisans & 177 & 2,76 & 0,65 & & \\
\hline & Lisansüstü & 42 & 2,66 & 0,85 & & \\
\hline \multirow{4}{*}{ Genel Doyum } & Sağlık meslek lisesi & 44 & 3,12 & 0,39 & \multirow{4}{*}{4,79} & \multirow{4}{*}{0,01} \\
\hline & önlisans & 45 & 3,26 & 0,57 & & \\
\hline & Lisans & 177 & 2,93 & 0,59 & & \\
\hline & Lisansüstü & 42 & 2,88 & 0,84 & & \\
\hline
\end{tabular}

Tablo 3'te ANOVA testiyle Doyum boyutları ve eğitim durumu arasındaki ilişki incelenmiş ve anlamlı fark bulunmuştur. Yapılan Sidak testinde her doyum boyutunda lisans ve lisansüstünün sağlık meslek lisesi ve önlisans mezunlarına göre doyumunun anlamlı biçimde daha yüksek olduğu görülmüştür.

Tablo 4: İş Yerinde Kıdem ve Boyutlar

\begin{tabular}{|c|c|c|c|c|c|c|}
\hline Boyutlar & İş Yerindeki Kıdem & $\mathbf{N}$ & $x$ & S.S & $\mathbf{F}$ & $\mathbf{p}$ \\
\hline \multirow{4}{*}{ İçsel Doyum } & 1 yıldan az & 7 & 3,45 & 0,49 & \multirow{4}{*}{0,81} & \multirow{4}{*}{0,49} \\
\hline & $1-5$ yıl & 99 & 3,21 & 0,66 & & \\
\hline & 6-10 yıl & 57 & 3,21 & 0,62 & & \\
\hline & 11 yıl ve üzeri & 145 & 3,14 & 0,61 & & \\
\hline \multirow{4}{*}{ Dışsal Doyum } & 1 yıldan az & 7 & 3,38 & 0,94 & \multirow{4}{*}{5,17} & \multirow{4}{*}{0,01} \\
\hline & $1-5$ yıl & 99 & 2,93 & 0,67 & & \\
\hline & 6-10 yıl & 57 & 2,90 & 0,68 & & \\
\hline & 11 yıl ve üzeri & 145 & 2,67 & 0,66 & & \\
\hline \multirow{4}{*}{ Genel Doyum } & 1 yıldan az & 7 & 3,41 & 0,69 & \multirow{4}{*}{2,90} & \multirow{4}{*}{0,04} \\
\hline & $1-5 \mathrm{yll}$ & 99 & 3,07 & 0,63 & & \\
\hline & $6-10 \mathrm{yıl}$ & 57 & 3,06 & 0,60 & & \\
\hline & 11 yıl ve üzeri & 145 & 2,90 & 0,60 & & \\
\hline
\end{tabular}

Tablo 4'te ANOVA testiyle doyum boyutları ile iş yerindeki kıdem arasındaki ilişki incelenmiş ve dışsal doyum ile genel doyumda anlamlı fark bulunmuştur. Yapılan Sidak testinde 11 yıl ve üzeri süreyle iş yerinde çalışanların diğerlerine göre dışsal ve genel doyum bakımından anlamlı derecede daha düşük doyum puanlarına sahip olduğu görülmüştür.

Tablo 51: Stres Tipi ve Boyutlar

\begin{tabular}{|c|c|c|c|c|c|c|}
\hline Boyutlar & Stres tipi & $\mathbf{n}$ & $x$ & s.s & $\mathbf{F}$ & $\mathbf{p}$ \\
\hline \multirow{5}{*}{ İçsel Doyum } & B TiP & 11 & 3,26 & 0,76 & \multirow{5}{*}{33,89} & \multirow{5}{*}{0,01} \\
\hline & с TiP & 77 & 3,64 & 0,40 & & \\
\hline & D TiP & 136 & 3,09 & 0,48 & & \\
\hline & E TiP & 42 & 3,00 & 0,43 & & \\
\hline & F Tip & 42 & 2,94 & 0,81 & & \\
\hline \multirow{5}{*}{ Dışsal Doyum } & B TiP & 11 & 3,09 & 0,92 & \multirow{5}{*}{24,27} & \multirow{5}{*}{0,01} \\
\hline & с TiP & 77 & 3,22 & 0,54 & & \\
\hline & D TiP & 136 & 2,84 & 0,53 & & \\
\hline & E TiP & 42 & 2,60 & 0,40 & & \\
\hline & F Tip & 42 & 2,59 & 0,91 & & \\
\hline \multirow{5}{*}{ Genel Doyum } & B TIP & 11 & 3,17 & 0,83 & \multirow{5}{*}{33,75} & \multirow{5}{*}{0,01} \\
\hline & с TiP & 77 & 3,43 & 0,44 & & \\
\hline & D TiP & 136 & 3,01 & 0,44 & & \\
\hline & E TiP & 42 & 2,80 & 0,35 & & \\
\hline & F TiP & 42 & 2,63 & 0,83 & & \\
\hline
\end{tabular}


Analiz sonuçlarına göre içsel, dışsal doyum ve genel doyum boyutunda ise katılımcıların stres tiplerinin ortalama boyut puanlarının birbirlerinden farklı olduğu tespit edilmiştir ( $\mathrm{Fi}=33,89 \mathrm{Fd}=24,27, \mathrm{Fg}=33,75, \mathrm{p}<0,05)$. Farklılı̆ıı sebebine bakıldığında içsel doyum, dışsal ve genel doyum boyutunda $B$ ve $C$ tipi kişilerin ortamla içsel doyum, dışsal ve genel doyum puanlarının D tipi, E Tipi ve $F$ Tipi bireylere göre daha yüksek olduğu tespit edilmiștir(p<0,05).

Sonuçlara göre bireylerin Stres düzeyleri azaldıkça iş doyumu düzeylerinin de azaldığı tespit edilmiştir. Çalışmada en yüksek stres düzeyine sahip olan B tipi ve C tipi kişilerin D, E ve F tipi gruplara göre daha yüksek oranlarda iş doyumuna sahip olduğu tespit edilmiştir.

Tablo 6: Gelir ve Boyutlar

\begin{tabular}{|c|c|c|c|c|c|c|}
\hline Boyutlar & Gelir Düzeyi & $\mathbf{n}$ & $x$ & s.s & $\mathbf{F}$ & $\mathbf{p}$ \\
\hline & Gelir Giderden Az & 164 & 3,08 & 0,68 & & \\
\hline \multirow{3}{*}{ İçsel Doyum } & Gelir Gider Denk & 20 & 3,23 & 0,27 & 4,94 & 0,01 \\
\hline & Gelir Giderden Fazla & 124 & 3,31 & 0,56 & & \\
\hline & Gelir Giderden Az & 164 & 2,79 & 0,76 & & \\
\hline \multirow[t]{3}{*}{ Dışsal Doyum } & Gelir Gider Denk & 20 & 2,44 & 0,49 & 4,36 & 0,01 \\
\hline & Gelir Giderden Fazla & 124 & 2,91 & 0,58 & & \\
\hline & Gelir Giderden Az & 164 & 2,94 & 0,68 & & \\
\hline \multirow[t]{2}{*}{ Genel Doyum } & Gelir Gider Denk & 20 & 2,83 & 0,34 & 3,64 & 0,03 \\
\hline & Gelir Giderden Fazla & 124 & 3,11 & 0,53 & & \\
\hline
\end{tabular}

Tablo 6'da katılımcıların İçsel, Dışsal doyum ve Genel doyum boyutu puanlarının aylık gelir durumlarına göre farklı olduğu tespit edilmiştir $(\mathrm{Fi}=4,94, \mathrm{Fd}=4,36, \mathrm{Fg}=3,46, \mathrm{p}<0,05)$. Farkın sebebine bakıldığında geliri giderine denk ve geliri giderinden fazla olan katılımcıların iş doyumu düzeylerinin gideri gelirinden yüksek olan katılımcılara göre daha yüksek düzeyde olduğu tespit edilmiştir.

Doyum boyutları arasındaki ilişkiyi incelemek adına korelasyon analizi uygulanmıştır.Buna göre; içsel doyum-Dışsal doyum: 0,765; Dışsal doyum-Genel doyum: 0,945; İçsel doyum- Genel doyum: 0,934 olmak üzerepozitif düzeyli anlamlı ilişki bulunmuştur.

Tablo 82: Stres Puanları ile İş Doyumu Arasındaki ilişskinin İncelenmesi

\begin{tabular}{|c|c|c|c|c|}
\hline İlişki Düzeyi & & İçsel Doyum & Dışsal Doyum & Genel Doyum \\
\hline \multirow{2}{*}{ İş Stresi } & $r$ &,$- 561 * *$ &,$- 514^{* *}$ &,$- 571 * *$ \\
\hline & $p$ & 0,01 & 0,01 & 0,01 \\
\hline
\end{tabular}

Tablo 8'de elde edilen sonuçlara göre bireylerin stres puanları ile içsel doyum boyutu arasında anlamlı ve negatif yönde orta güçte anlamlı bir ilişkinin olduğu tespit edilmiştir Bireylerin stres puanları arttıkça içsel doyum puanlarının azaldığı tespit edilmiştir. Bireylerin stres puanları ile dışsal doyum boyutu arasında anlamlı ve negatif yönde bir ilişkinin olduğu tespit edilmiştir $(r=-0,514, p<0,05)$. Bireylerin stres puanları arttıkça dışsal doyum puanlarının azaldığı tespit edilmiştir. Katılımcıların stres puanları ile genel doyum boyutu arasında anlamlı ve negatif yönde bir ilişkinin olduğu tespit edilmiştir $(r=-0,571, p<0,05)$. Bireylerin stres puanları arttıkça genel doyum puanlarının azaldığı tespit edilmiştir.

İş doyumu alt boyutları hem kendi arasında hem de stres puanlarına göre ilişki olduğu tespit edilmiştir. Stres tipi ile iş doyumu negatif yönde ilişkili iken iş doyumu alt boyut puanları kendi aralarında oldukça yüksek sayılabilecek bir düzeyde pozitif yönde ilişkilidir.

Tablo 9: Regresyon Modelleri

\begin{tabular}{|c|c|c|c|c|c|c|c|}
\hline \multirow[t]{2}{*}{ Bağımlı değişkenler } & \multicolumn{3}{|c|}{ Modelin Test Edilmesi } & \multicolumn{4}{|c|}{ Bağımsız değişkenler } \\
\hline & $\mathrm{R} 2$ & $\begin{array}{l}\text { Katsayılar } \\
(p<0,05)\end{array}$ & Model $(p<0,05)$ & $\begin{array}{l}\text { İçsel } \\
\text { Doyum }\end{array}$ & $\begin{array}{l}\text { Dışsal } \\
\text { Doyum }\end{array}$ & $\begin{array}{l}\text { Genel } \\
\text { Doyum }\end{array}$ & $\begin{array}{l}\text { Stres } \\
\text { puanları }\end{array}$ \\
\hline İçsel Doyum & 0,34 & Anlamlı & Anlamlı & - & 0,20 & 0,16 & $-0,29$ \\
\hline Dışsal Doyum & 0,79 & Anlamlı & Anlamlı & 0,22 & - & 0,22 & $-0,88$ \\
\hline Genel Doyum & 0,62 & Anlamlı & Anlamlı & 0,33 & 0,11 & - & $-0,44$ \\
\hline
\end{tabular}

Tablo 9'da içsel doyumu en çok etkileyenin Stres puanları olduğu görülmüştür. Toplamda içsel doyumun değişimi \%34 oranında olup yüksek olmamakla birlikte anlamlılık teşkil eden yeterli bir orandır. Dışsal doyumu en çok etkileyenin Stres puanları olduğu görülmüştür. Toplamda bu üç değişken modeldeki değişimleri tek başlarına \%79 oranında açıklamaktadır. Bu oranın oldukça yeterli olacağı düşünülebilir. Genel doyumu en çok etkileyenin Stres puanları olduğu görülmüştür. Toplamda bu üç değişkenin modeldeki değişimleri \%62 oranında açıklamaktadır. Bu oran yeterli olarak kabul edilebilir.

Bu bulgular haricinde; Katılımcıların Yaş ve Doyum Boyutları arasındaki ilişki, Mesleki Genel Kıdem ve Doyum Boyutları arasındaki ilişki incelenmiş ve aralarında anlamlı bir fark bulunamamıştır. Bu yüzden tabloların sunuma dahil edilmesi gerekli görülmemiştir. 


\section{SONUÇ}

Bu sonuçlara göre çalışmada $\mathrm{H} 1$ hipotezi "Akdeniz Üniversitesi Hastanesindeki sağlık çalışanlarının iş tatmini düzeyleri ile iş stresi düzeyleri arasında negatif ilişki vardır." kabul edilir. Bu sonuçlara göre hemşirelerin çalışma ortamındaki iş streslerini artıracak durumların oluşması iş doyumunu azaltacaktır.

$B$ ve $C$ gruplarındaki hemşirelerin iş doyumu düzeyleri $D, E, F$ tiplerine göre daha yüksek olduğu tespit edilmiştir. Çalışmada en yüksek stres düzeyine sahip olarak tespit edilen grubun $B$ Grubu $(n=11)$ olduğu görülmüştür. $A$ ve $B$ Grubu stres düzeyinde olan kişilerin stresli $C$ ve $D$ Grubu kişilerin orta düzey stresli, E ve F Grubu kişilerin ise düşük düzeyde stresli olduğu söylenebilir. İ̧̧ verimliliği, motivasyon ve iş doyumu çerçevesinde en optimal düzeyin C ve D Grupları olduğundan bahsedebiliriz. Sınırın üzerinde strese sahip olma durumu iş doyumu üzerinde olumlu yönde etki edebilir. Bunun tersi olarak da düşük stres gruplarının (E ve F Tip) daha düşük düzeyde iş doyumu yaşadıkları düşünülebilmektedir. H2 Hipotezi "Akdeniz Üniversitesi Hastanesindeki sağlık çalışanlarının stres tiplerine göre iş tatmini düzeyleri farklıdır." kabul edilmektedir.

Elde edilen bulgulara göre işini severek yapma, eğitim düzeyi, mesleki kıdem ve gelir gider dengesi durumlarının hemşirelerin içsel, dışsal ve genel (İş Tatmini) düzeyleri üzerinde etkili olduğu tespit edilmiştir. Medeni hal, yaş ve iş yeri kıdemlerinin hemşirelerin içsel, dışsal ve genel (İş Tatmini) düzeyleri üzerinde etkili olmadığı tespit edilmiştir. Buna göre H3 Hipotezi “Akdeniz Üniversitesi Hastanesindeki sağlık çalışanlarının demografik ve iş ile ilgili özellikleri iş tatmini üzerinde etkilidir." kısmen ret kısmen kabul edilir. Hipote zhemşirelerin;Medeni hal, yaş ve iş yeri kıdemi göre İşini severek yapma, eğitim düzeyi, mesleki kıdem ve gelir gider dengesi durumları kapsamında ise kabul edilir.

Katılımcıların eğitim durumu, gelir düzeyi, iş yerindeki kıdem ve işini isteyerek yapma durumu gibi değişkenlerin iş doyumuna önemli oranda etki ettiklerini görmekteyiz. İş streslerinden bazılarının ve belirli düzeyde olanların iş doyumunu olumlu etkilediği görülmüştür. (B tipi ve C Tipi) 11 yıl ve üzeri aynı iş yerinde çalışanların iş doyumunda azalmalar gerçekleştiği sonucu ortaya konmuştur. Araştırma sonuçlarını genel olarak değerlendirildiğinde hemşirelerin iş streslerinin iş doyumlarını olumsuz etkilediği ortaya konulmuştur. Buna göre; sağlık yöneticileri, sağlık çalışanlarına önemli olduklarının kendilerine ve yaptıkları işlere saygı duyduklarını hissettirmeleri gerektiği, varsa olumsuz fiziki şartları düzeltmeleri gerektiği, hizmet içi eğitim programları, sosyal organizasyonlar ve aktiviteler düzenlenmesi gerektiği, öncesi ve sonrasında iş stresi ve tatmin durumları değerlendirilip fayda tespit edilen yönünde hareket edilmesi gerektiği fazla iş yükünü hafifletecek uygulamalar yapılması gerekliliği ve kalite standartları çerçevesinde iş stresi ve iş tatmini düzeylerinin de değerlendirilmesi sağlanmalıdır.

\section{KAYNAKLAR}

Baltaş, A., Baltaş, Z. (1998). Stres ve başa çikma yolları. İstanbul: Remzi Yayınları.

Cohen, S., Williamson, G. M. (1991). Stress and infectious disease in humans. Psychological bulletin, $109(1), 5$.

Davis, K., John, W. (1989). Newstrom human behavior at work, organizational behavior, 8. Edition. McGraw Hill Book Company, Newyork, 1989: 177 .

Şimşek, M. Ş., Akgemci, T., Çelik, A. (2007). Davraniş bilimlerine giriş ve örgütlerde davranış. Nobel Yayın Dağıtım Ankara, 2007: 139-150.

Şahin, Z. (2011). Bir devlet hastanesinde çalişan hemşireler ile bir vakif üniversitesi hastanesinde çalişan hemşirelerin iş stres ve iş doyumu düzeylerinin incelenmesi. Maltepe Üniversitesi(MaÜ), SBE Psikoloji Anabilim Dalı(PAD) Endüstri Ve Örgüt Psikolojisi Programı(EÖPP), YLT, İstanbul, Ekim 2011: 11-39. 